\title{
Australian cardiac rehabilitation exercise parameter characteristics and perceptions of high-intensity interval training: a cross-sectional survey
}

This article was published in the following Dove Press journal: Open Access Journal of Sports Medicine

\author{
Amanda L Hannan' \\ Wayne Hing' \\ Mike Climstein ${ }^{2}$ \\ Jeff S Coombes ${ }^{3}$ \\ James Furness ${ }^{1}$ \\ Rohan Jayasinghe ${ }^{4-6}$ \\ Joshua Byrnes ${ }^{7}$
}

'Faculty of Health Sciences \& Medicine, Bond University, Gold Coast, QLD, Australia; ${ }^{2}$ Exercise Health and Performance Faculty Research Group, Faculty of Health Sciences, The University of Sydney, Sydney, NSW, Australia; ${ }^{3}$ School of Human Movement and Nutrition Sciences, The University of Queensland, Brisbane, QLD, Australia; ${ }^{4}$ Cardiology Department, Gold Coast University Hospital, Gold Coast, QLD, Australia; ${ }^{5} \mathrm{G}$ riffith University, Gold Coast, QLD, Australia; ${ }^{6}$ Macquarie University, Sydney, NSW, Australia; ${ }^{7}$ Centre for Applied Health Economics, School of Medicine, Griffith University, Logan, QLD, Australia
Correspondence: Amanda L Hannan Faculty of Health Sciences \& Medicine, Bond University, 2 Promethean Way, Robina, QLD 4226, Australia

Tel +6 I 4 I55। 0772

Fax +6I 75595 I652

Email mhannan@bond.edu.au
Purpose: This study explored current demographics, characteristics, costs, evaluation methods, and outcome measures used in Australian cardiac rehabilitation (CR) programs. It also determined the actual usage and perceptions of high-intensity interval training (HIIT).

Methods: A cross-sectional observational web-based survey was distributed to 328 Australian CR programs nationally.

Results: A total of 261 programs completed the survey (79.6\% response rate). Most Australian CR programs were located in a hospital setting (76\%), offered exercise sessions once a week (52\%) for 6-8 weeks (49\%) at moderate intensity (54\%) for 46-60 min (62\%), and serviced $101-500$ clients per annum (38\%). HIIT was reported in only $1 \%$ of programs, and $27 \%$ of respondents believed that it was safe while $42 \%$ of respondents were unsure. Lack of staff $(25 \%)$, monitoring resources $(20 \%)$, and staff knowledge (18\%) were the most commonly reported barriers to the implementation of HIIT. Overall, Australian CR coordinators are unsure of the cost of exercise sessions.

Conclusion: There is variability in CR delivery across Australia. Only half of programs reassess outcome measures postintervention, and cost of exercise sessions is unknown. Although HIIT is recommended in international CR guidelines, it is essentially not being used in Australia and clinicians are unsure as to the safety of HIIT. Lack of resources and staff knowledge were perceived as the biggest barriers to HIIT implementation, and there are inconsistent perceptions of prescreening and monitoring requirements. This study highlights the need to educate health professionals about the benefits and safety of HIIT to improve its usage and patient outcomes. Keywords: coronary artery disease, exercise, interval training, cardiovascular disease

\section{Plain language summary}

A survey of Australian cardiac rehabilitation (CR) programs assessed demographics, evaluation, costs, and usage of high-intensity interval training (HIIT). Most programs were from a rural, hospital-based setting and performed once a week for 6-8 weeks at moderate intensity, and costs of CR are essentially unknown. HIIT is only used by $1 \%$ of programs; clinicians are uncertain of its safety and lack of resources was the biggest barrier.

\section{Introduction}

Cardiac rehabilitation (CR) is an important tool in the secondary prevention of cardiovascular disease (CVD) and aims to assist participants to lead full, active lives, while reducing the risk of further cardiac events. ${ }^{1,2} \mathrm{CR}$ involves comprehensive education, lifestyle behavior modification interventions, psychosocial counseling, and supervised 
exercise programs. ${ }^{3}$ These exercise programs aim to increase the cardiorespiratory fitness and the strength of participants.

Cardiorespiratory fitness has a direct correlation with improved prognosis in cardiac patients, ${ }^{4-6}$ and CR programs should, therefore, ensure that the exercise prescription improves maximal cardiorespiratory fitness. Evaluation of the extent of change should be measured to allow comparisons of the effectiveness of different exercise methods. Two commonly used exercise methods are moderate-intensity continuous training (MICT) and high-intensity interval training (HIIT). MICT involves exercising at moderate exercise intensity (usually $60-75 \%$ of maximal heart rate [MHR]) continuously for a prolonged period (30-60 min). HIIT involves intense exercise bouts ( $>80 \%$ of MHR) for $30 \mathrm{~s}$ to 4 min interspersed with low-intensity exercise (40-50\% of MHR) for $30 \mathrm{~s}$ to $4 \mathrm{~min}$ as active recovery. ${ }^{7}$ Research has shown HIIT improves cardiorespiratory fitness levels, particularly peak oxygen uptake $\left(\mathrm{VO}_{2}\right.$ peak) by twice as much as $\mathrm{MICT}^{8}$ In cardiac-specific populations, there have been systematic reviews supporting that HIIT improves cardiorespiratory fitness more than MICT. ${ }^{9-13}$ A systematic review by Ismail et $\mathrm{al}^{14}$ concluded that participants with heart failure increased peak oxygen consumption by $23 \%$ when engaged in HIIT compared with $13 \%$ when engaged in MICT.

Guidelines for patients with CVD strongly influence clinicians' practice worldwide as they are formulated from evidence-based research. The American Heart Association, American College of Sports Medicine, European Association for Cardiovascular Prevention and Rehabilitation, Canadian Association of Cardiac Rehabilitation, and American Association of Cardiovascular and Pulmonary Rehabilitation Guidelines endorse moderate-to-vigorous intensity exercise, while Australia, New Zealand, Japan, and the UK favor lower intensity exercise. ${ }^{15}$ Current Australian CR guidelines recommend $\geq 30$ min of low-to-moderate intensity physical activities. For CR participants with high levels of fitness who aim to return to high-intensity physical activity, the Australian guidelines suggest that HIIT may be appropriate with medical consent. ${ }^{16}$

The usage of HIIT in CR is currently unknown in Australia. As emerging research is highlighting the superior ability for HIIT to improve cardiorespiratory fitness and thus reduce mortality compared to current practice, investigation into current exercise practice, evaluation, and usage of HIIT is timely. Understanding the perceptions toward HIIT implementation will provide greater insight and highlight barriers for usage. This may lead to improved adoption of HIIT as an exercise tool in Australian CR programs.
The purpose of this study was to 1) explore current demographics, characteristics, and cost of outpatient Australian CR programs; 2) identify cardiorespiratory exercise evaluation practices and additional outcome measures; 3 ) establish the usage of HIIT; and 4) collate clinicians' perceptions around HIIT, particularly safety, barriers, prescreening, and monitoring requirements.

\section{Methods Design}

This was a cross-sectional, observational study using a webbased questionnaire (SurveyMonkey Inc., Palo Alto, CA, USA), and ethics approval (RO 1846) was granted from Bond University's Human Research Ethics Committee. Questions included both drop-down selection options and open-ended responses. Open-ended responses were then grouped into common themes. The survey comprised questions to investigate CR exercise parameters of dose (frequency, duration, and intensity), mode, staff type, participation numbers, adherence and uptake rates, and cost. Additionally, questions regarding whether HIIT was safe and perceived barriers of HIIT implementation were asked. Finally, CR coordinators were asked whether reducing the exercise time per session would be beneficial for CR uptake.

The questionnaire was initially peer reviewed by members of the Australian Cardiovascular Health and Rehabilitation Association's (ACRA) Executive Committee. In addition, university academics reviewed the survey. Modifications were made by incorporating the feedbacks received. Eight Queensland (Australia) sites were subsequently used to pilot the survey prior to distributing nationally.

\section{Inclusion criteria}

Australian CR programs that delivered on-site outpatient exercise sessions for people with coronary artery disease were eligible to participate. CR programs that were publicly listed on the National Heart Foundation of Australia and ACRA databases were screened for inclusion.

\section{Exclusion criteria}

CR programs that only delivered inpatient sessions, only provided education, or only serviced patients with heart failure were excluded.

\section{Recruitment}

The CR program coordinators were initially contacted via email with an overview of the research, a participant consent form, and a link to the survey. Consent was assumed once 
participants accessed the link. These documents were accompanied by a letter of support from ACRA. Further reminder emails were sent on a monthly basis. To ensure a high response rate, a further email or phone call was made to remind the program coordinators of the closing date of the survey.

\section{Data analysis}

All responses were included in the analysis, despite whether the entire survey was completed by individual sites. Percentages were calculated using individual response rates for each question. Responses were downloaded into Excel and analyzed as descriptive statistics, namely mean, frequency, and percentage.

\section{Results}

A total of 328 surveys were distributed, of which 261 programs responded ( $79.6 \%$ of response rate). Table 1 presents demographic and exercise characteristics of Australian CR programs.

\section{Exercise training intensity}

Reported exercise training intensity was used to determine whether programs were implementing HIIT, which was defined as exercise at intensities $>85 \%$ of MHR. A total of 171 programs $(79.2 \%)$ responded to this question. Of these, only $1 \%$ (two programs) reported prescribing high-intensity exercise. Figure 1 depicts the percentage of programs that identified ranges of intensities including light- $(50-60 \%$ of MHR), moderate- (61-75\% of MHR), vigorous- ( $75-85 \%$ of MHR), and high-intensity exercise/vigorous to high ( $>85 \%$ of MHR).

\section{Exercise capacity testing: type/frequency}

A total of $216(83 \%)$ programs responded to the question about type and frequency of exercise capacity tests performed. The majority (80\%) of respondents reported performing a 6-min walking test (6MWT), 7\% reported other walking tests, $4 \%$ reported using a cycle ergometer test, $3 \%$ utilized a stress test or step test, and $8 \%$ did no exercise capacity testing.

The frequency of exercise capacity evaluation included testing before participation, upon the completion of $\mathrm{CR}$ and 3, 6, and 12 months postcompletion of CR. The majority $(90 \%)$ of programs performed exercise capacity tests before patients attended CR and 56\% repeated these tests upon completion of the programs. This postcompletion testing dropped to 16,11 , and $7 \%$ of programs performing tests at 3, 6, and 12 months follow-up, respectively. In addition, 9\% of programs performed no exercise capacity testing.

\section{Additional outcome measures}

The majority (92.1\%) of programs utilized outcome measures in addition to cardiorespiratory fitness tests. A third or more

Table I Demographics and characteristics: numbers of responses (percentages) of Australian CR programs

\begin{tabular}{|c|c|c|c|c|c|c|c|}
\hline \multicolumn{2}{|c|}{ Setting: $n=253$} & \multicolumn{2}{|c|}{ Location: $n=254$} & \multicolumn{2}{|c|}{ Size: $n=246$} & \multicolumn{2}{|l|}{ States: $n=24$ I } \\
\hline Rural & $105(42)$ & Hospital & $191(76)$ & $<50$ & $74(30)$ & New South Wales & $88(37)$ \\
\hline Major city & $88(35)$ & Nonhospital & $63(24)$ & $50-100$ & $66(27)$ & Victoria & $79(33)$ \\
\hline \multirow[t]{5}{*}{ Regional } & $60(23)$ & & & $101-500$ & $93(38)$ & Queensland & $43(18)$ \\
\hline & & & & $>500$ & $13(5)$ & South Australia & $23(9)$ \\
\hline & & & & & & Tasmania & $4(2)$ \\
\hline & & & & & & Australian Capital Territory & $3(1)$ \\
\hline & & & & & & Northern Territory & $\mathrm{I}(0.01)$ \\
\hline \multicolumn{2}{|c|}{$\begin{array}{l}\text { Number of participants/ } \\
\text { session: } n=\mid 46\end{array}$} & \multicolumn{2}{|c|}{$\begin{array}{l}\text { Duration } \\
\text { (weeks): } n=|8|\end{array}$} & \multicolumn{2}{|c|}{$\begin{array}{l}\text { Frequency } \\
\text { (per/week): } n=198\end{array}$} & \multicolumn{2}{|l|}{$\begin{array}{l}\text { Duration of individual } \\
\text { sessions ( } \mathrm{min}): \mathrm{n}=213\end{array}$} \\
\hline$<8$ & $33(23)$ & $4-6$ & $78(43)$ & 1 & $103(52)$ & $15-30$ & $13(6)$ \\
\hline $8-11$ & $63(43)$ & $6-8$ & $88(49)$ & 2 & $86(43)$ & $31-45$ & $36(17)$ \\
\hline $12-15$ & $34(23)$ & $8-10$ & $\mathrm{I}(0.0 \mathrm{I})$ & 3 & $4(2)$ & $46-60$ & $133(62)$ \\
\hline \multirow[t]{2}{*}{$>15$} & $16(11)$ & $10-14$ & $14(8)$ & 4 & $0(0)$ & $61-120$ & $11(6)$ \\
\hline & & & & 5 & $5(3)$ & Variable & $20(9)$ \\
\hline \multicolumn{2}{|c|}{ Staff:participant ratio: $n=62$} & \multicolumn{2}{|c|}{ Percentage uptake: $\mathbf{n = 2 2 0}$} & \multicolumn{4}{|c|}{ Percentage adherence: $\mathbf{n = 2 0 2}$} \\
\hline$<1: 3$ & $8(13)$ & $<30$ & $22(10)$ & $<30$ & & $10(5)$ & \\
\hline $\mid: 3$ & $7(11)$ & $31-50$ & $43(20)$ & $31-60$ & & $30(15)$ & \\
\hline 1:4 & $12(19)$ & $5 I-80$ & $114(52)$ & $61-90$ & & $140(70)$ & \\
\hline $\mathrm{I}: 5$ & $17(28)$ & $>80$ & $4 \mid(18)$ & $>90$ & & $22(10)$ & \\
\hline$>1.5:<1: 10$ & $10(16)$ & & & & & & \\
\hline$>1: 10$ & $8(13)$ & & & & & & \\
\hline
\end{tabular}

Abbreviation: $C R$, cardiac rehabilitation. 


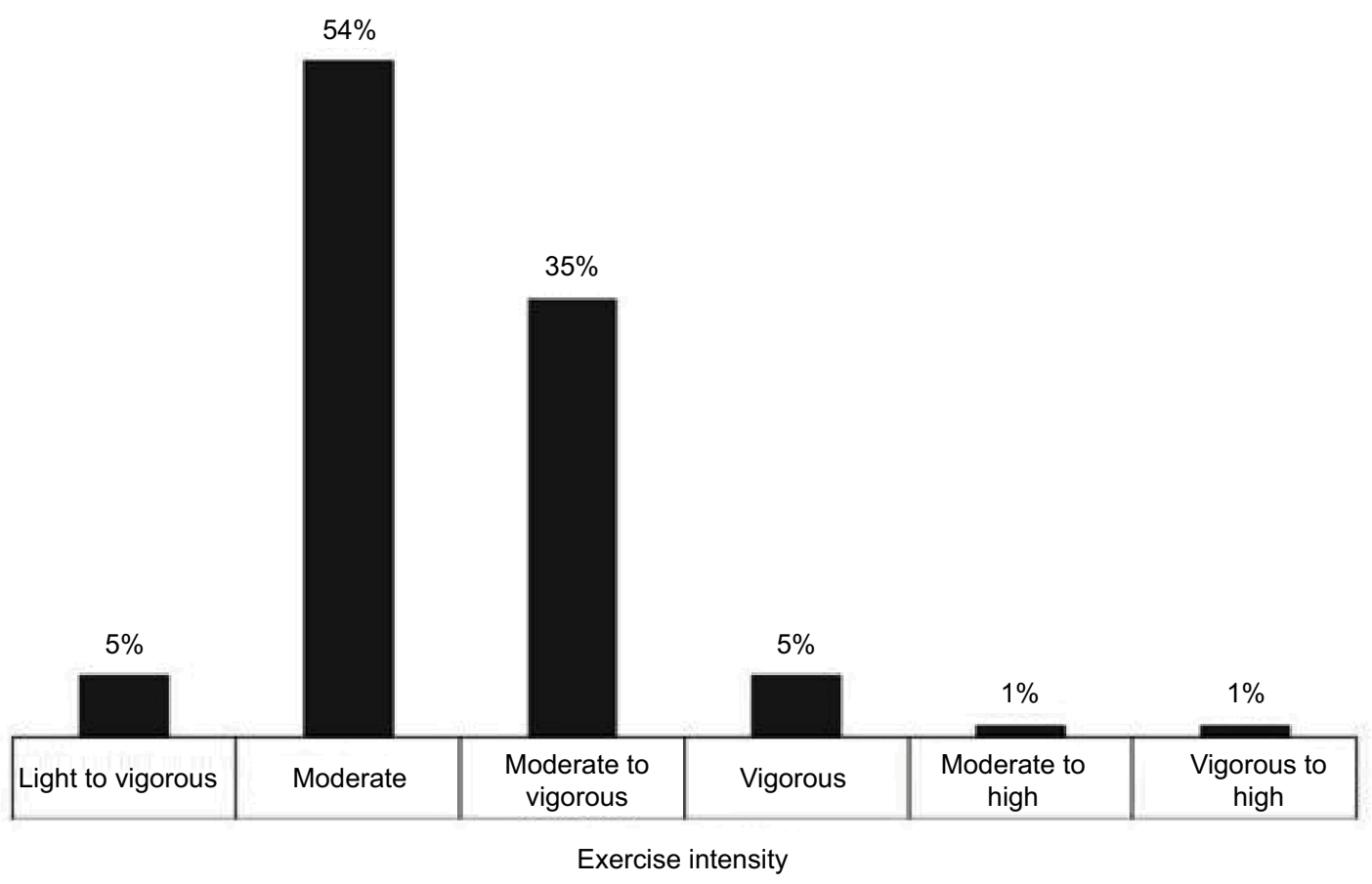

Figure I Percentages of national exercise intensity prescription in cardiac rehabilitation $(n=|7|)$.

programs assessed anthropometric measures. Two-thirds of programs measured height, body mass index, and waist circumference, and the greatest percentage of programs (89\%) measured weight. Less than a third of programs screened for comorbidities (musculoskeletal and sternal stability testing) and other measures including quality of life, depression scale, resting and peak exercising heart rates, blood pressure, and balance tests. Strength was the least commonly used measure with $7 \%$ of programs assessing it. Figure 2 depicts the percentages of additional outcome measures used within Australian CR.

\section{Perceptions of HIIT}

HIIT was thought to be safe by $27 \%$ of the $209(80 \%)$ respondents with $42 \%$ being unsure and $31 \%$ believing it to be unsafe. There were $190(73 \%)$ respondents who identified perceived barriers to HIT implementation. The survey allowed each program to identify multiple barriers. The most commonly identified barriers, such as lack of staff, monitoring resources, and staff knowledge, were only identified by a quarter to one-fifth of programs. Additional barriers were identified by between $6 \%$ and $14 \%$ of programs, and only $4 \%$ reported perceiving no barriers. Figure 3 shows the percentage of perceived barriers reported for each category.
Of the 201 (77\%) respondents, $80 \%$ believed that different prescreening of fitness would be necessary if implementing HIIT, $56 \%$ of whom, reported that a submaximal graded exercise test would be necessary and $28 \%$ chose others (including step test and 6MWT). The need for different screening requirements were identified by $19 \%$ of respondents, however this group were unsure as to what type of test should be used. Only $9 \%$ reported that testing could be the same as current practice and $6 \%$ felt that a $\mathrm{VO}_{2}$ max test should be used as a prescreening tool for HIIT.

Of the 202 respondents (77\%), more than one half (64\%) reported that they believed monitoring using an external device would be required when implementing HIIT. These devices included a heart rate monitor (46\%), 3 lead electrocardiogram (ECG) via telemetry (13\%) and 12 Lead ECG via telemetry (5\%). In addition, a further $13 \%$ of respondents believed different monitoring was necessary, however, they did not identify the type of monitoring and $22 \%$ were unsure about monitoring requirements.

Of the $211(81 \%)$ respondents to the question asking whether halving the exercise session times would benefit the CR service, $44 \%$ of respondents reported being unsure, $36 \%$ of respondents believed that it would not be beneficial, and $19 \%$ of respondents reported that it would benefit their CR service.

Of the $210(80 \%)$ respondents, the majority $(82 \%)$ believed that by reducing exercise time by half, there would 


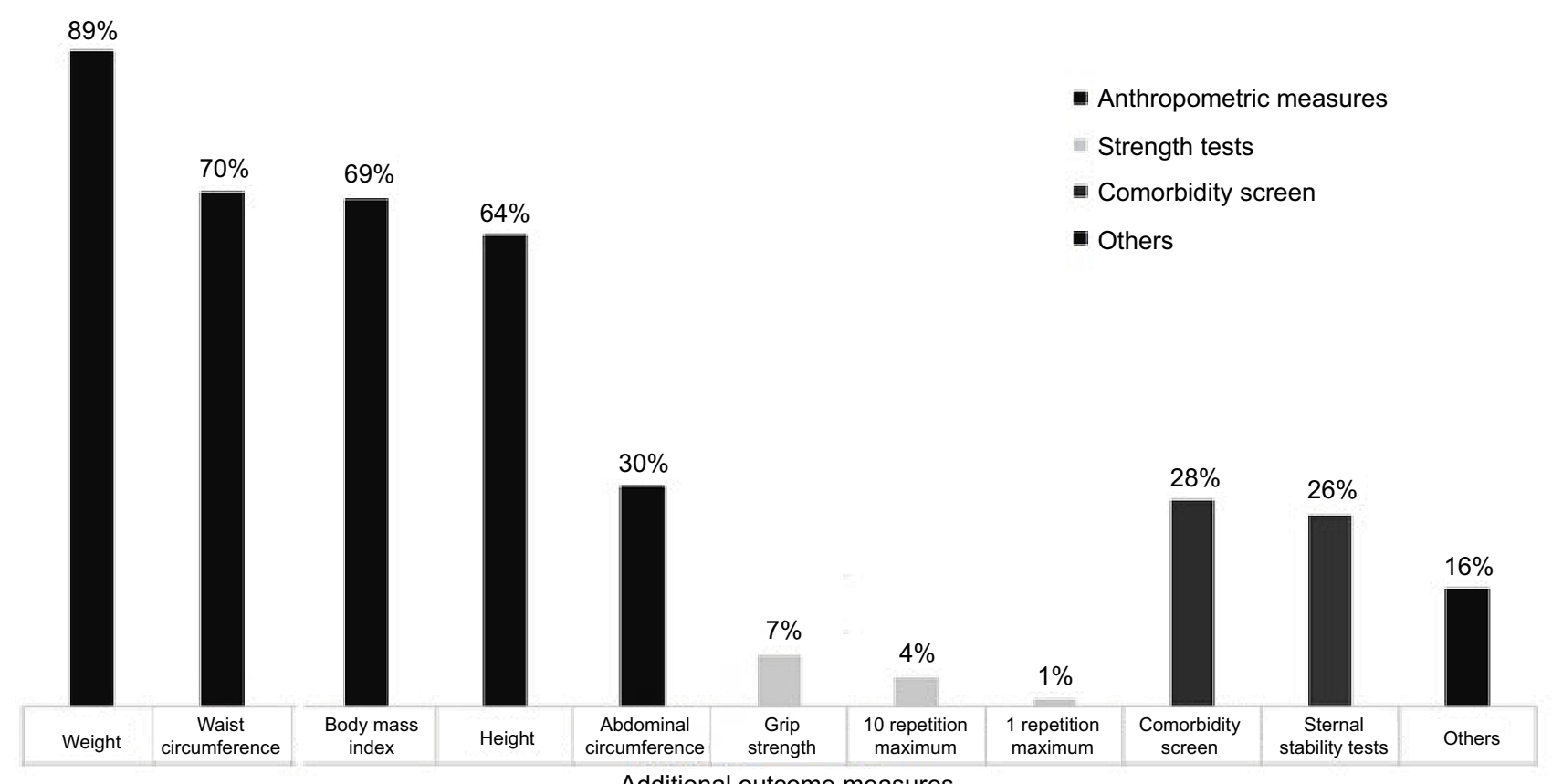

Figure 2 Percentages of additional outcome measures assessed nationally $(n=199)$.

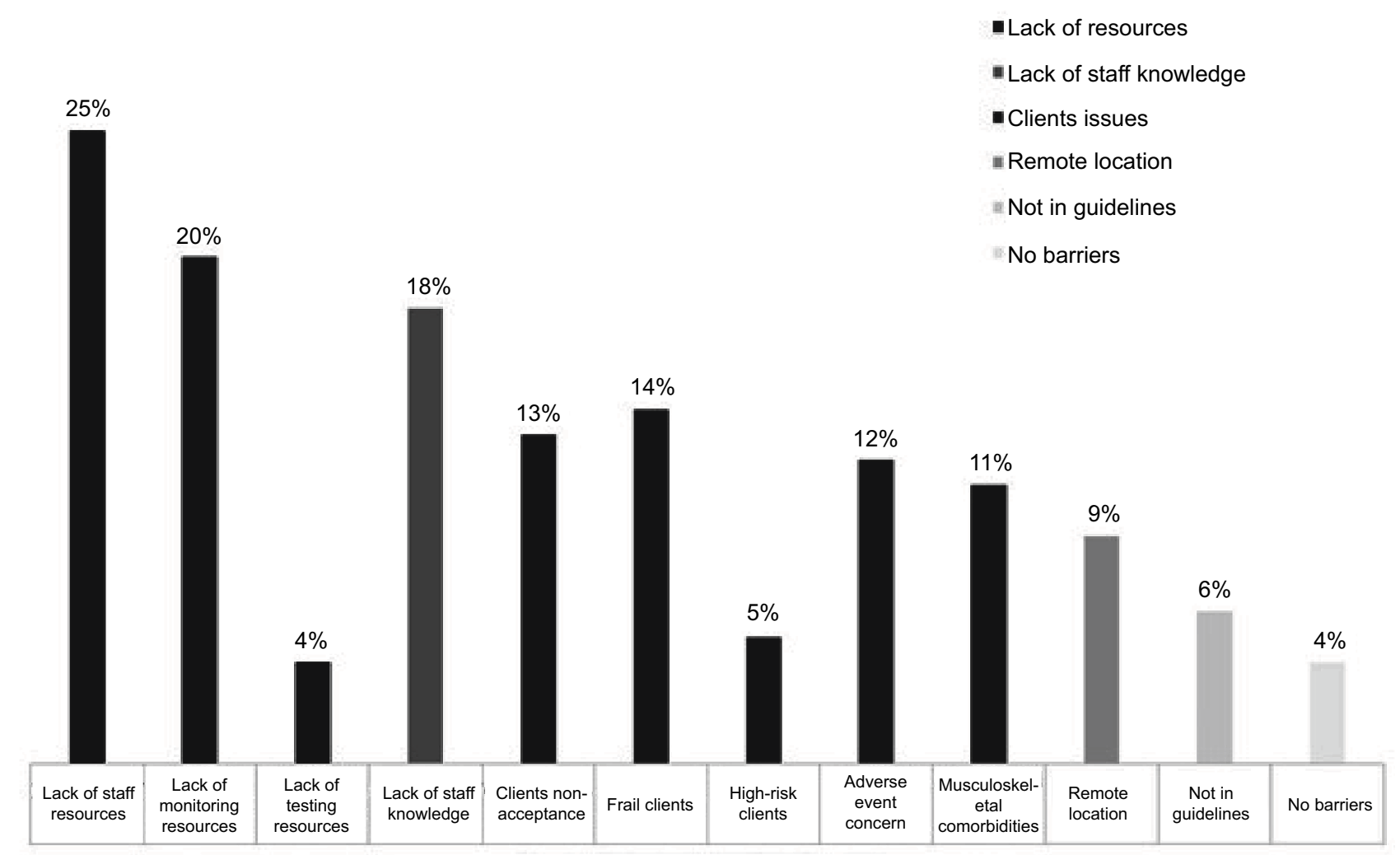

Perceived barriers to HIIT implementation

Figure 3 Percentages of national cardiac rehabilitation coordinators' perceptions of barriers to HIIT implementation $(n=190)$.

Abbreviation: HIIT, high-intensity interval training.

be a $<10 \%$ improvement in uptake into $\mathrm{CR}$ programs. In addition, $12 \%$ of respondents felt that it would improve $\mathrm{CR}$ uptake between $11 \%$ and $50 \%$ and $6 \%$ of respondents believed that it would increase uptake by $>50 \%$. 


\section{Cost}

CR coordinators were asked to estimate the cost of conducting an exercise session in their CR program. There were 179 (67\%) responses. Most respondents (61\%) stated that they were unsure of the cost, with only $39 \%$ responding with a dollar value. The majority of programs (68\%) estimated the sessions to cost $<\$ 449$.

Alternatively, $4 \%$ provided a cost per annum ranging between $\$ 15,000$ and $\$ 500,000$ with the majority (63\%) stating that costs were between $\$ 15,000$ and $\$ 50,000$. Table 2 depicts the cost values of exercise sessions estimated by clinicians. Answers were given in cost per session and/or amounts per annum.

\section{Discussion}

This research aimed to collate national demographic information, characteristics, and economic cost of Australian CR programs and ascertain the actual usage of HIIT and perceptions surrounding the safety, barriers, prescreening, monitoring requirements, and uptake of HIIT. The high response rate (79.6\%) provided insight into Australian CR practice and perceptions surrounding HIIT.

There have been numerous international surveys published investigating CR practices. ${ }^{17-33}$ Most of these focused on program characteristics such as referral rates, adherence, location, staff mix, patient characteristics, program duration, and frequency. ${ }^{17-20,22-24,26-31,33}$ Several surveys have collated information regarding exercise testing, ${ }^{22,24-26,30,33}$ and only four surveys describe the intensity of exercise. ${ }^{22,23,25,31}$ Five surveys collected data on costs of CR sessions. ${ }^{18,22,23,32,33}$

\section{Demographics and characteristics of CR programs}

Most programs responding to our survey were from New South Wales and Victoria and primarily geographically located in a rural, hospital-based setting (76\%). This is similar to what has previously been reported internationally. Most international surveys reported that $>70 \%$ of programs are located in medical facilities, primarily hospitals. ${ }^{20,24} \mathrm{In}$ England, the location of CR was reported as being 55\% in the hospital setting, $23 \%$ in both hospital and community centers, and $16 \%$ in leisure settings. ${ }^{33}$

We found that most CR programs (42\%) cater for between 101 and 500 participants annually. According to the National Heart Foundation of Australia, in 2012-2013, there were almost four and a half million admissions to hospital for CVD and an additional $3.4 \%$ of people reported a diagnosis of heart attack and ischemic heart disease. ${ }^{34}$ If the 328 programs identified by the Heart Foundation and ACRA databases each catered for 500 participants per year (overestimation of capacity), this would only allow 164,000 participants access to $\mathrm{CR}$. This suggests that current capacity for CR may not be meeting demand.

Our study found that most CR exercise sessions are conducted between 6 and 8 weeks' duration. This is similar to the duration offered in Europe (mean 8 weeks), ${ }^{26}$ England (mean 7.1 weeks), ${ }^{33}$ India (6-18 weeks) ${ }^{19}$ and Ireland (mean 7.4 weeks). ${ }^{29}$ The duration is shorter than that offered in Brazil (3-6 months), ${ }^{31}$ Canada (5 months), ${ }^{20}$ Latin America, and the Caribbean (11-15 weeks). ${ }^{23}$ The USA did not report the number of weeks CR sessions were offered to participants, however, 19-36 individual sessions are offered instead. ${ }^{28}$

CR aims to assist participants to forge exercise as a lifelong habit. There is research to support the need for exercise to be performed consistently four times per week for a minimum of 6 weeks to form a habit. ${ }^{35}$ However, we found that CR programs in Australia only offer sessions once per week and rely upon participants performing exercise at home to complement supervised CR sessions. Since the average rates of performance of exercise at home have been found to be only $47 \%,{ }^{36}$ it is uncertain whether CR participants will perform exercises frequently enough for them to become a habit or meet recommended exercise guidelines ( $>150$ min per week). ${ }^{3}$ If participants failed to perform the recommended amount of exercise, the degree of cardiorespiratory fitness gained could

Table 2 Clinician's perception on cost of cardiac rehabilitation in Australia $(n=69)$

\begin{tabular}{ll|lc}
\hline Cost per session (\$) Number of respondents (\%) & Cost per annum (\$) Number of respondents (\%) \\
\hline$<149$ & $19(28)$ & $15,000-50,000$ & $5(7)$ \\
$150-299$ & $13(19)$ & $300,000-500,000$ & $3(4)$ \\
$300-449$ & $15(22)$ & \\
$450-600$ & $6(9)$ & \\
$600-750$ & $1(1)$ & \\
$750-999$ & $1(1)$ & \\
$>1,000-3,000$ & $6(9)$ & \\
\hline
\end{tabular}


be compromised. Australian programs offer considerably less frequent sessions than international countries. Canada, ${ }^{20}$ England, ${ }^{33}$ the Netherlands, ${ }^{25}$ Latin America and Caribbean ${ }^{23}$ have reported offering sessions 2-3 times a week. Ireland ${ }^{29}$ and Europe ${ }^{26}$ reported offering sessions four times a week, and the USA offered 3.6 \pm 0.9 sessions/week. ${ }^{27}$ Italy offered the most frequent number of sessions (5.16 \pm 1.4 sessions/ week). ${ }^{30}$

Most programs reported that $51-80 \%$ of eligible participants referred to $\mathrm{CR}$, enroll, and a fifth of programs reported an uptake of $80 \%$. This is higher than what has previously been reported as surveys across several countries have shown $14-43 \%$ of potential cardiac patients actually participate in CR programs. ${ }^{37}$ Previous literature states onefifth to one-third of patients enrolling complete CR. ${ }^{38-40} \mathrm{The}$ current study found that the majority of programs reported an adherence rate between 61 and $90 \%$. This suggests adherence to Australian CR to be at least twice the rate previously reported. However, this higher rate may be due to programs only offering sessions once per week.

\section{Exercise capacity tests and frequency}

Most Australian CR programs (80\%) used the 6MWT to ascertain the exercise capacity of participants. This test is costeffective and requires minimal equipment. However, collection of information regarding blood pressure, heart rhythm, or hemodynamic responses to exercise can be problematic without expensive ECG telemetry equipment. Information pertaining to the hemodynamic response to exercise is particularly important for people with cardiac disease, and $<1 \%$ of programs reported performing a maximal or submaximal exercise test, despite this test being identified as the gold standard by the American College of Sports Medicine. ${ }^{7}$ Maximal exercise tests have been shown to be the most accurate in determining maximal aerobic capacity. ${ }^{7}$ The majority of research studies include $\mathrm{VO}_{2}$ peak testing using ECG monitoring, therefore, there appears to be disparity between research and clinical implementation of exercise. There is considerable variation worldwide in the exercise capacity testing methods and frequency used within CR. Canada reported the highest percentage of programs $(90 \%)$ that offer exercise stress testing. ${ }^{20}$ This was followed by the Netherlands reporting that $76 \%$ of programs perform a symptom-limited test and $8 \%$ of programs test respiratory exchange. ${ }^{25}$ England reported that $71 \%$ of programs use a graded treadmill exercise test, $50 \%$ of programs use a shuttle test, $25 \%$ of programs use a step test, and $29 \%$ of programs do not perform any test. ${ }^{33}$ In Ohio, USA, it was reported that $78 \%$ of programs obtained stress tests for participants if an exercise physiologist was on staff compared with $56 \%$ of programs with no exercise physiologist. ${ }^{24}$ Japan reported low rates of cardiopulmonary testing (14-23\%), ${ }^{22}$ and in Italy, $89 \%$ of programs perform a 6MWT to gauge exercise capacity. ${ }^{30}$

To evaluate the effectiveness of an intervention, assessments such as exercise capacity changes should be performed before and following a CR intervention. In addition, as cardiovascular fitness is a strong predictor of subsequent events within this population, ${ }^{5}$ long-term benefits $(3,6$, and 12 months) of the intervention should be assessed. However, our survey results identified that approximately one half $(56 \%)$ of all CR programs reassessed fitness levels postintervention. The percentage of programs assessing fitness levels during 3,6 , and 12-month follow-ups, steadily declined the longer the participant had been discharged from CR. This indicates that Australian CR programs are not adequately reassessing exercise capacity, and therefore, evaluation of the effectiveness of current exercise prescription techniques is questionable. The reporting of the percentage of programs that retest cardiovascular fitness is lacking worldwide, with only Europe reporting $16 \%$ of programs retest ${ }^{26}$ and England reporting $55 \%$ of programs retest fitness on the completion of CR. ${ }^{33}$

\section{Additional outcome measures}

The current study found that anthropometric measures were the most commonly used outcome measures and were used by over two-thirds of programs. A third of programs also included abdominal circumference measures. This is not surprising as these tests are inexpensive and quick to implement.

Muscular strength has been previously suggested to be an important component of CR. ${ }^{41}$ However, we found that only $10 \%$ of programs assessed strength changes resulting from participation in CR. This suggests that the evaluation of the effectiveness of current exercise prescription, in improving strength, seems to be lacking.

Patients who have undergone coronary artery bypass graft surgery (CABG) comprise a large subsection of participants in CR programs, ${ }^{7}$ and research has shown that $16.3 \%$ of patients who undergo CABG via a median sternotomy develop sternal instability that interferes with daily living. ${ }^{42}$ Although patients who have had CABG should be screened for sternal instability prior to initiating a progressive resistance training program, another interesting finding of our results was the apparent lack of testing for sternal instability. Only a quarter of CR programs reported performing sternal stability testing. Our findings thus suggest that some participants may be unknowingly placed at risk of sternal injury or increased risk of dehiscence. These additional outcome measures have not been reported internationally. 


\section{HIIT}

\section{Usage and perceptions of safety}

The survey identified an underutilization of HIIT with only $1 \%$ of programs reporting HIIT usage. Furthermore, only a quarter of CR coordinators believed that HIIT was a safe form of rehabilitative exercise, despite no research, to the author's knowledge, supporting this belief. Using a retrospective analysis of 4,846 patients with CVD, Rognmo et a ${ }^{43}$ analyzed 175,820 hours of CR exercise training for rates of adverse events. With regard to safety, they found that one fatal event was reported per 129,456 hours of MICT and two nonfatal events were reported per 23,182 hours of HIIT and concluded that the risk of adverse events was low in both modes of rehabilitative exercise. Rognmo et a $1^{43}$ recommended the use of HIIT in CR for people with coronary artery disease due to the significant cardiovascular adaptations gained from its use. In addition, 12 RCTs, which compared MICT with HIIT, ${ }^{44-55}$ reported only one adverse cardiac event in the HIIT exercise groups, orthostatic collapse, which did not require hospitalization. ${ }^{54}$ In the MICT groups, one serious adverse event was reported (acute MI requiring surgical intervention $24 \mathrm{~h}$ postexercise) and two participants showed significant ST depression on exercise tests requiring percutaneous coronary intervention after 6 weeks of training. ${ }^{48}$ Therefore, the current evidence does not suggest HIT to be unsafe or to lead to increased adverse cardiovascular events compared to MICT. Furthermore, as HIIT improves cardiorespiratory fitness to a greater extent than MICT, HIIT may provide participants a higher degree of risk reduction and reduce mortality, making it safer in the long term than MICT. The belief that HIIT is unsafe may be contributing to the lack of adoption of this model in Australian CR.

\section{Perceived barriers to HIIT implementation}

Our results showed that a lack of resources, specifically staffing $(25 \%)$ and monitoring $(20 \%)$, was the biggest perceived barrier to HIIT implementation. However, the National Heart Foundation of Australia recommends one staff member per 10 participants for $\mathrm{CR}^{3}$ and our findings showed programs currently cater for twice the recommended minimum staff. This seems to be incongruent with guidelines.

Lack of HIIT knowledge was a commonly $(18 \%)$ reported barrier to HIIT implementation. This is not surprising as a recent Australian study reported nurses as being the largest group of health professionals supervising CR exercise (87\%) and the second largest group to prescribe exercise programs as treatment, with physiotherapists being the second largest to supervise exercise (66\%). ${ }^{56}$ Nursing staff may not have had formal training in exercise prescription as found in an American study, which reported $92 \%$ of nurses surveyed indicated that they had no formal training in exercise prescription. ${ }^{57}$ It would be of interest to identify the level of formal exercise training given to Australian nursing staff. Furthermore, these results highlight the need to investigate whether Australian CR programs are utilizing health professionals who are best qualified to prescribe/supervise exercise within their programs. Physiotherapists are more commonly involved in CR than nurses in Germany (36 vs $25 \%$ ), ${ }^{32}$ the Netherlands (93 vs $12 \%$ ), ${ }^{25}$ and India ${ }^{19}$ where the majority of staff are physiotherapists. Cardiologists (77\%) and physiotherapists (89\%) staff the CR programs in Italy ${ }^{30}$ and Latin America and Caribbean countries (100 and 94\%, respectively) ${ }^{23}$ Nurses (66\%) and exercise physiologists (38\%) dominate programs in the USA with minimal physical therapy input $(2 \%){ }^{28}$

A total of $13 \%$ of respondents reported client's nonacceptance as being a barrier to HIIT implementation. It is unclear whether this is due to the perception by staff that participants would not enjoy this type of exercise or whether participants would believe it to be unsafe. A study using Physical Activity Enjoyment Scale results reported that 92\% of participants who engaged in HIIT enjoyed this exercise significantly more than MICT. ${ }^{58}$ This preference for HIIT was also found in another study where $>50 \%$ of participants preferred HIIT over MICT, ${ }^{59}$ further highlighting the possible incongruence in respondents' beliefs about the degree of patient's nonacceptance.

\section{Perceived prescreening practices}

The majority of respondents to the survey believed that a graded exercise test would be required prior to implementing HIIT. Australian practices would need to cater for the addition of such tests when implementing HIIT; however, it could be argued that these tests should become standard practice for all CR participants to allow an evidence-based exercise prescription. ${ }^{7}$

\section{Uptake}

A lack of time has previously been reported in the literature as the most common reason that Australian adults do not engage in regular physical activities. ${ }^{60} \mathrm{~A}$ further study involving 2,236 adults and analyzing barriers to physical activities found that lack of time was most commonly identified (55\%) as a barrier to participation. ${ }^{61}$ This evidence suggests 
that reducing the time of exercise sessions in CR programs by implementing HIIT may improve uptake; yet program responders do not seem to agree.

\section{Cost}

Our study showed that Australian CR coordinators are unsure of the cost of a CR exercise session. This lack of knowledge of costs by clinicians is similar to that found in Latin America and Caribbean which showed that 79\% of programs did not know the costs associated with CR, $9 \%$ of programs reported the cost $>\$ 150,000 /$ year, and $9 \%$ reported in excess of this. ${ }^{23}$ There is further variability in cost estimations of CR worldwide. In Germany, the cost was estimated to be $€ 75-87 /$ day, ${ }^{32}$ England reported the mean cost per patient as $£ 288,{ }^{33}$ and Japan estimated the cost as $\$ 42 / \mathrm{h} .{ }^{22}$ Further studies investigating the actual costs of Australian CR programs would be beneficial in determining the most cost-effective treatment.

\section{Limitations}

The survey was not designed to require respondents to answer each question before proceeding to the next, which may have created some response bias. This resulted in missing data. Definitions were not given, and some open-ended questions were open to interpretation. Although a pilot survey was performed, no reliability testing was undertaken. The survey was sent to CR coordinators; however, the type of health professional each respondent represented was not identified.

\section{Conclusion}

Results identified that CR in Australia is mostly performed once per week for 6-8 weeks for 41-60 min duration at a moderate intensity, which may not be sufficient in allowing participants to adopt exercise as a lifelong habit. The evaluation of the effectiveness of current Australian CR programs in improving exercise capacity and muscular strength is lacking with just under half of programs failing to perform reassessments. CR coordinators are also unsure as to the cost of their current CR services.

Although HIIT has been recommended in international CR guidelines, it is not being utilized in Australia and program respondents are unsure as to the safety of HIIT. Lack of resources and knowledge was perceived as the biggest barrier to HIIT implementation, and there are inconsistent perceptions on prescreening and monitoring requirements.

This study highlights the need to improve exercise capacity and muscular strength evaluation methods of current practice in CR. It also emphasizes the need to educate Australian clinicians regarding safety, enjoyment, and physiological benefits of HIIT. Failure to do so may hinder the adoption of HIIT and potentially disadvantage suitable patients who could reap the superior physiological and cardio-protective benefits associated with HIIT.

Results of this survey could be helpful to the personnel responsible for designing CR programs in Australia. Increasing the frequency of sessions, re-evaluating the effectiveness of the exercise sessions through repeated outcome measures, and introducing HIIT should be considered. A further survey may be warranted in a 5-year timeframe to further assess Australian practices.

\section{Acknowledgment}

The research did not receive any specific grant from funding agencies in the public, commercial, or not-for-profit sectors.

\section{Disclosure}

The authors report no conflicts of interest in this work.

\section{References}

1. Heran B, Chen J, Ebrahim S, et al. Exercise-based cardiac rehabilitation for coronary heart disease. Cochrane Database Syst Rev. 2011;7:CD001800.

2. Taylor RS, Brown A, Ebrahim S, et al. Exercise-based rehabilitation for patients with coronary heart disease: systematic review and meta-analysis of randomised controlled trials. Am J Med. 2004;116(10):682-692.

3. National Heart Foundation of Australia [homepage on the Internet] Secondary Prevention of Cardiovascular Disease. 2010. Available from: http://heartfoundation.org.au/. Accessed February 27, 2018.

4. Meyer J, Prakash M, Froelicher V, Do D, Partington S, Atwood JE. Exercise capacity and mortality among men referred for exercise testing. $N$ Engl J Med. 2002;346(11):793-801.

5. Swain D, Franklin B. Comparison of cardioprotective benefits of vigorous versus moderate intensity aerobic exercise. Am J Cardiol. 2006;97(1):141-147.

6. Keteyian S, Brawner C, Savage P, et al. Peak aerobic capacity predicts prognosis in patients with coronary heart disease. Am Heart $J$. 2008;156(2):292-300.

7. Pescatello LS. ACSM's Guidelines for Exercise Testing and Prescription. 9th ed. Philadelphia: WoltersKluwer/Lippincott Williams \&Williams Health; 2014.

8. Weston K, Wisloff U, Coombes J. High-Intensity interval training in patients with lifestyle-induced cardiometabolic disease: a systematic review and meta-analysis. Br J Sports Med. 2014;48(16):1227-1234.

9. Cornish A, Broadbent S, Cheema B. Interval training for patients with coronary artery disease: a systematic review. Eur J Appl Physiol. 2011;111(4):579-589.

10. Elliott AD, Rajopadhyaya K, Bentley D, Beltrame J, Aromataris E. Interval training versus continuous exercise in patients with coronary artery disease: a meta-analysis. Heart Lung Circ. 2015;24(2):149-157.

11. Pattyn N, Coeckelberghs E, Buys R, Cornelissen V, Vanhees L. Aerobic interval training vs. moderate continuous training in coronary artery disease patients: a systematic review and meta-analysis. Sports Med. 2014;44(5):687-700.

12. Liou K, Ho S, Fildes J, Ooi S. High intensity interval versus moderate intensity continuous training in patients with coronary artery disease: a meta-analysis of physiological and clinical parameters. Heart Lung Circ. 2016;25(2):166-174. 
13. Hannan A, Hing W, Simas V, et al. High-intensity interval training versus moderate-intensity continuous training within cardiac rehabilitation: a systematic review and meta-analysis. Open Access J Sports Med. 2018;9:1-17.

14. Ismail H, McFarlane J, Nojoumian A, Dieberg G, Smart N. Clinical outcomes and cardiovascular responses to different exercise training intensities in patients with heart failure. A systematic review and metaanalysis. JACC Heart Fail. 2013;1(6):514-522.

15. Price K, Gordon B, Bird S, Benson A. A review of guidelines for cardiac rehabilitaiton exercise programmes: Is there an international consensus? Eur J Prev Cardiol. 2016;23(16):1715-1733.

16. Woodruffe S, Neubeck L, Clark R, et al. Australian Cardiovascular Health and Rehabilitation Association (ACRA) core components of cardiovascular secondary prevention and cardiac rehabilitation 2014. Heart Lung Circ. 2015;24(5):430-441.

17. Humphrey R, Guazzi M, Niebauer J. Cardiac rehabilitation in Europe. Prog Cardiovasc Dis. 2014;56(5):551-556.

18. Bethell H, Lewin R, Dalal H. Cardiac rehabilitation in the United Kingdom. Heart. 2009;95(4):271-275.

19. Madan K, Babu A, Contractor A, Sawhney J, Prabhakaran D, Gupta R. Cardiac rehabilitation in India. Prog Cardiovasc Dis. 2014;56(5):543-550.

20. Grace S, Bennett S, Ardern C, Clark A. Cardiac rehabilitation series: Canada. Prog Cardiovasc Dis. 2014;56(5):530-535.

21. McGee H, Hevey D, Horgan J; Irish Association of Cardiac Rehabilitation. Cardiac rehabilitation service provision in Ireland: the Irish Association of Cardiac Rehabilitation survey. Ir J Med Sci. 2001;170(3): 159-162.

22. Goto Y. Current state of cardiac rehabilitation in Japan. Prog Cardiovasc Dis. 2014;56(5):557-562.

23. Korenfeld Y, Mendoza-Bastidas C, Saavedra L, et al. Current status of cardiac rehabilitation in Latin America and the Carribean. Am Heart J. 2009;158(3):480-487.

24. Zullo M, Jackson L, Whalen C, Dolansky M. Evaluation of the recommended core components of cardiac rehabilitation. AN OPPORTUNITY FOR QUALITY IMPROVEMENT. J Cardiopulm Rehabil Prev. 2012;32(1):32-40.

25. Vromen T, Spee R, Kraal J, et al. Exercise training programs in Dutch cardiac rehabilitation centres. Neth Heart J. 2013;21(3):138-143.

26. Benzer W, Rauch B, Schmid J, et al; EuroCaReD Study Group. Exercisebased cardiac rehabilitation in twelve countries results of the European cardiac rehabilitation registry. Int J Cardiol. 2017;228:58-67.

27. Pack Q, Squires R, Lopez-Jimenez F, et al. Participation rates, process monitoring, and quality improvement among United States Cardiac Rehabilitation Programs: A National Survey. J Cardiopulm Rehabil Prev. 2015;35(3):173-180.

28. Kaminsky L, Thur L, Riggin K. Patient and program characteristics of early outpatient cardiac rehabilitation programs in the United States. J Cardiopulm Rehabil Prev. 2013;33(3):168-172.

29. Delaney M, Flynn R, Kiernan M, et al. Third National Survey of Cardiac Rehabilitation Service Provision in Ireland: Progress on the 1999 National Cardiovascular Health Strategy Recommendations. Royal College of Surgeons in Ireland: Ireland; 2006.

30. Griffo R, Tramarin R, Volterrani M, et al. Italian Survey on Cardiac Rehabilitation (ISYDE.13-directory): report on structures, organization and programs of rehabilitation cardiology in Italy. G Ital Cardiol. 2015;16:1-8.

31. Borghi-Silva A, Goncalves Mendes R, Trimer R, Cipriano G Jr. Current trends in reducing cardiovascular disease risk factors from around the world: focus on cardiac rehabilitation in Brazil. Prog Cardiovasc Dis. 2014;56(5):536-542.

32. Karoff M, Held K, Bjarnason-Wehrens B. Cardiac rehabilitation in Germany. Eur J Cardiovasc Prev Rehabil. 2007;14(1):18-27.

33. Brodie D, Bethell H, Breen S. Cardiac rehabilitation in England: a detailed national survey. Eur J Cardiovasc Prev Rehabil. 2006;13(1):122-128.

34. Nichols M, Peterson K, Herbert J, Alston L, Allender S. Australian Heart Disease Statistics 2015. Melbourne: National Heart Foundation of Australia; 2016.
35. Kaushal N, Rhodes R. Exercise habit formation in new gym members: a longitudinal study. J Behav Med. 2015;38(4):652-663.

36. Sheeran P. Intention-behavior relations: a conceptual and empirical review. Eur Rev Soc Psychol. 2002;12(1):1-36.

37. Bethell H, Turner S, Evans J, Rose L. Cardiac rehabilitation in the United Kingdom. HOW COMPLETE IS THE PROVISION? J Cardiopulm Rehabil. 2001;21(2):111-115.

38. Daly J, Sindone A, Thompson D, Hancock K, Chang E, Davidson P. Barriers to participation in and adherence to cardiac rehabilitation programs: a critical literature review. Prog Cardiovasc Nurs. 2002;17(1):8-17.

39. Yohannes AM, Yalfani A, Doherty P, Bundy C. Predictors of drop-out from an outpatient cardiac rehabilitation programme. Clin Rehabil. 2007;21(3):222-229.

40. Lynggaard V, Nielsen C, Zwisler A, Taylor R, May O. The patient education - learning and coping strategies - improves adherence in cardiac rehabilitation (LC-REHAB): a randomised controlled trial. Int J Cardiol. 2107;236:65-70.

41. McCartney N, McKelvie R, Haslam D, Jones N. Usefulness of weightlifting training in improving strength and maximal power output in coronary artery disease. Am J Cardiol. 1991;67(11):939-945.

42. El-Ansary D, Adams R, Toms L, Elkins M. Sternal instbility following coronary artery bypass grafting. Physiother Theory Pract. 2000;16(1): 27-33.

43. Rognmo Ø, Moholdt T, Bakken H, et al. Cardiovascular risk of highversus moderate-intensity aerobic exercise in coronary heart disease patients. Circulation. 2012;126(12):1436-1440.

44. Jaureguizar K, Vicente-Campos D, Bautista L, et al. Effect of high intensity interval versus continuous exercise training on functional capacity and quality of life in patients with coronary artery disease: A RANDOMIZED CLINICAL TRIAL. J Cardiopulm Rehabil Prev. 2016;36(2):96-105.

45. Rocco E, Prado D, Silva A, et al. Effect of continuous and interval exercise training on the PETCO2 response during a graded exercise test in patients with coronary artery disease. Clinics. 2012;67(6):623-627.

46. Currie K, Dubberley J, McKelvie R, MacDonald M. Low-volume, high-intensity interval training in patients with CAD. Med Sci Sports Exerc. 2013;45(8):1436-1442.

47. Benetti M, de Araujo CL, dos Santos RZ. Cardiorespiratory fitness and quality of life at different exercise intensities after myocardial infarction. Arq Bras Cardiol. 2010;95(3):399-404.

48. Conraads VM, Pattyn N, De Maeyer C, et al. Aerobic interval training and continuous training equally improve aerobic exercise capacity in patients with coronary artery disease: the SAINTEX-CAD study. Int J Cardiol. 2015;179:203-210.

49. Keteyian S, Hibner B, Bronsteen K, et al. Greater improvement in cardiorespiratory fitness using higher-intensity interval training in the standard cardiac rehabilitation setting. J Cardiopulm Rehabil Prev. 2014;34(2):98-105.

50. Kim C, Choi H, Lim M. Effect of high interval training in acute myocardial infarction patients with drug-eluting stent. Am J Phys Med Rehabil. 2015;94(10 suppl 1):879-886.

51. Rognmo Ø, Hetland E, Helgerud J, Hoff J, Slordahl S. High intensity aerobic interval exercise is superior to moderate intensity exercise for increasing aerobic capacity in patients with coronary artery disease. Eur J Cardiovasc Prev Rehabil. 2004;11(3):216-222.

52. Moholdt T, Aamot I, Granøien I, et al. Aerobic interval training increases peak oxygen uptake more than usual care exercise training in myocardial infarction patients: a randomized controlled study. Clin Rehabil. 2011;26(1):33-44.

53. Cardozo G, Oliveira R, Farinatti P. Effects of high intensity interval versus moderate continuous training on markers of ventilatory and cardiac efficiency in coronary heart disease patients. ScientificWorldJournal. 2015;2015:8.

54. Munk P, Staal E, Butt N, Isaken K, Larsen A. High-intensity interval training may reduce in-stent restenosis following percutaneous coronary intervention with stent implantation. A randomised controlled trial evaluating the relationship to endothelial function and inflammation. Am Heart J. 2009;158(5):734-741. 
55. Amundsen BH, Rognmo $\varnothing$, Hatlen-Rebhan G, Slørdahl S. Highintensity aerobic exercise improves diastolic function in coronary artery disease. Scand Cardiovasc J. 2008;42(2):110-117.

56. Abell B, Glasziou P, Briffa T, Hoffmann T. Exercise training characteristics in cardiac rehabilitation programmes: a cross-sectional survey of Australian practice. Open Heart. 2016;3(1):e000374.

57. Dauenhauer J, Podgorski C, Karuza J. Prescribing exercise for older adults: a needs assessment comparing primary care physicians, nurse practitioners, and physician assistants. Gerontol Geriatr Educ. 2006;26(3):81-99.

58. Thum J, Parsons G, Whittle T, Astorino T. High-intensity interval training elicits higher enjoyment than moderate intensity continuous exercise. PLoS One. 2017;12(1):e0166299.
59. Jung ME, Bourne JE, Little JP. Where does HIT fit? An examination of the affective response to high-intensity intervals in comparison to continuous moderate- and continuous vigorous-intensity exercise in the exercise intensity-affect continuum. PLoS One. 2014;9(12): e114541.

60. Booth M, Bauman A, Owen N, Gore C. Physical activity preferences, preferred sources of assistance, and perceived barriers to increased activity among physically inactive Australians. Prev Med. 1997;26(1):131-137.

61. Sequeira S, Cruz C, Pinto D, Santos L, Marques A, Carreiro da Costa F. Prevalence of barriers for physical activity in adults according to gender and socioeconomic status. Br J Sports Med. 2011;45(15): A18-A19.

\section{Publish your work in this journal}

The Open Access Journal of Sports Medicine is an international, peer-reviewed, open access journal publishing original research, reports, reviews and commentaries on all areas of sports medicine. The journal is included on PubMed. The manuscript management system is completely online and includes a very quick and fair

\section{Dovepress}

peer-review system. Visit http://www.dovepress.com/testimonials.php to read real quotes from published authors. 